\title{
Resource recovery from wastewater, solid waste, and waste gas: engineering and management aspects
}

\author{
Eldon R. Rene ${ }^{1} \cdot$ Jinyi $\mathrm{Ge}^{2} \cdot$ Gopalakrishnan $\mathrm{Kumar}^{3} \cdot$ Rajendra Prasad Singh $^{4} \cdot$ Sunita Varjani ${ }^{5}$ \\ Published online: 18 April 2020 \\ (C) Springer-Verlag GmbH Germany, part of Springer Nature 2020
}

Acronym ICAFEE-ICWRS2018

The rapidly evolving environmental awareness and strict legislations in different countries have focused research towards the use of alternative fuels and also promoting sustainable biorefinery by utilizing waste materials as substrates. In general, the biodegradable wastes are identified as sources for high value-added compound recovery in framing the circular bioeconomy model. It is therefore noteworthy to mention that energy has become a crucial factor for humanity to continue the economic growth and social development, and maintain high living standard especially after the inauguration of the industrial revolution in the late eighteenth and early nineteenth century in both the developing and developed economies. With the global population swelling and industrialization is on the rise in many countries, humanity's hunger for energy has reached unprecedented levels. However, much of the world's energy is produced and consumed in ways that are not eco-friendly and environmentally sustainable. Moreover, more than half of our energy comes from fossil fuels that are extracted from deep within the Earth's crust. As fossil fuels are depleting day by day, there is a need to find out alternative renewable fuels to fulfill the energy demand of the world. More importantly, several major industries are currently looking to reduce their

\section{Responsible Editor: Philippe Garrigues}

Eldon R. Rene

e.raj@un-ihe.org

Jinyi Ge

jinyig@ princeton.edu

Gopalakrishnan Kumar

gopalakrishnanchml@gmail.com

Rajendra Prasad Singh

rajupsc@seu.edu.cn

Sunita Varjani

drsvs18@gmail.com dependence on fossil fuels and shift towards renewable energies systems. The manufacturing sector plays very important role for growth. Simultaneously, it also causes severe environmental problems. Water pollution is one of the major problems caused due to industrial growth. The accidental release of many chemicals by industrial process into the water bodies has been reported globally. As a result of this, the dissolved oxygen content of surface waters decreases, which threatens both the flora and fauna. It also poses negative effects on human lifestyles and the natural ecosystem. It has adverse impacts on the food chains. In most of the countries, there are several rules and regulations to control water pollution. The polluter pays principle setup life as principle of economics. However, the cost to treat the waste water is normally higher than its final selling price in many countries. Hence, government funding is required to support this type of policy approach. To regulate water pollution by industrial activities, in different countries, there are various policy instruments having different names such as environmental tax, pollution permits, water pricing, and industrial parks which act in and provide joint efforts to identify and monitor the polluters. This approaches would help to move towards promoting the sustainable development.
1 Department of Environmental Engineering and Water Technology, UNESCO-IHE Institute for Water Education, Westvest 7, 2611 AX Delft, the Netherlands

2 Civil and Environmental Engineering, E321 Engineering Quad, Princeton University, Princeton, NJ 08544, USA

3 Institute of Chemistry, Bioscience and Environmental Engineering, Faculty of Science and Technology, University of Stavanger, Box 8600 Forus, 4036 Stavanger, Norway

4 School of Civil Engineering, Southeast University, Nanjing 210096, China

5 Gujarat Pollution Control Board, Paryavaran Bhavan, CHH Road, Sector 10A, Gandhinagar, Gujarat 382 010, India 
On the other hand, rapid urbanization and industrial developments are the most crucial tool for the exploitation and pollution of the freshwater resources. Changes in climate and landscape utilization pattern are the serious concern for urban water ecosystems and for mankind. Increase in hard surface area, generation and mismanagement of wastewater, flooding, greenhouse gas emission, and many other factors are seriously destroying the freshwater resources in both qualitatively and quantitatively manners. Increase in temperature and other human activities are also key factors for water pollution and reduce the availability and utilization of water resources. Due to abovementioned factors, limited water availability and huge water demand becomes a serious challenge for urban planners and governing bodies. Recently, much research has been devoted to conducting field studies and developing new tools to simulate the impact of climate change and anthropogenic activities on aquatic environments, in order to understand the complex dynamics under different conditions. But keeping in mind the significant importance of water resources for mankind, it is still required to conduct the research on all the aspects of impact of climate change and anthropogenic activities, eutrophication, biogeochemical cycles, emerging pollutants in water environment, and flood resilience. Therefore, applied research and implementation of various water treatment facilities and technologies are the need of the day for protection and management of precious water resources.

The special issue covers the various advancement of research and innovations in the field of wastewater treatment and enhanced recovery of value added products from solid, liquid, and gaseous wastes. Specific topics covered in this include, among others, drought propagation to watershed scales, erosion characteristics of sandstone slopes, the applications of functionalized activated carbon, biofuel and its applications, treatment systems for drinking water, sustainable electricity management, and biochemical methane/energy potential from wastes. The guest editors of this special issue are thankful to the Editor-inChief of Environmental Science and Pollution Research (ESPR), Professor Philippe Garrigues for providing an opportunity to publish selected peer-reviewed papers that were presented at ICAFEE-ICWRS2018. Our special thanks to Ms. Fanny Creusot and Ms. Florence Delavaud, Editorial Assistants of ESPR and the entire production team at Springer for their valuable support in bringing out this issue successfully. We also thank all the reviewers for providing critical reviews, comments, and feedback on manuscripts that were submitted for this thematic special issue. On a personal note, the guest editors would like to thank Prof. Dafang Fu (Southeast University, China), Prof. Chris Zevenbergen (IHE Delft, The Netherlands), and Prof. Willium F. Hunt, III (North Carolina State University, USA) for chairing the ICAFEE/ICWRS 2018 event. We are grateful to acknowledge the efforts of our advisory scientific and organizing committee members for their untiring efforts to make the conference a grand success. We would like to thank all participants and authors for their hard work that have yielded this special issue a unique success. We firmly believe that you will enjoy reading the manuscripts presented in this special issue and also share the issue with your research team.

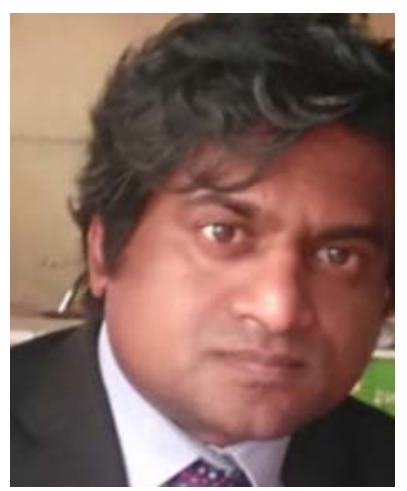

Eldon R. Rene is currently working as a Senior Lecturer at IHE Delft, Institute for Water Education, The Netherlands. He obtained his University Teaching Qualification (UTQ) diploma from IHE Delft and a PhD in Chemical Engineering from the Indian Institute of Technology Madras (India). Eldon's broad research interests are related to the development of biological treatment processes for wastewater and waste-gas treatment, resource recovery, and the use of artificial intelligence tools for environmental monitoring and environmental process control. He has published 3 books (Sustainable heavy metal remediation-Volume 1: Principles and processes, Volume 2: Case studies and Waste biorefinery: Integrating biorefineries for waste valorisation), more than 225 research/review articles in scientific journals, $\sim 50$ book chapters, $\sim 180$ conference papers, and 7 monographs. He is the associate and review editor of the Journal of Environmental Engineering (ASCE), editorial board member of Bioresource Technology Reports, review editor of Frontiers in Energy Research, and associate editor of Environmental Quality and Management. He has also edited several thematic special issues in the following journals: Bioresource Technology, Bioresource Technology Reports, Journal of Environmental Management, Environmental Science and Pollution Research, Journal of Environmental Engineering (ASCE), Chemosphere, AQUA (IWA publishing), Chemosphere, International Biodeterioration and Biodegradation, and AQUA. As a part of his educational and capacity building efforts, Eldon has taught scientific writing and skill development to $\sim 3000 \mathrm{MS}$ and $\mathrm{PhD}$ students in major international events or workshops held in 28 countries.

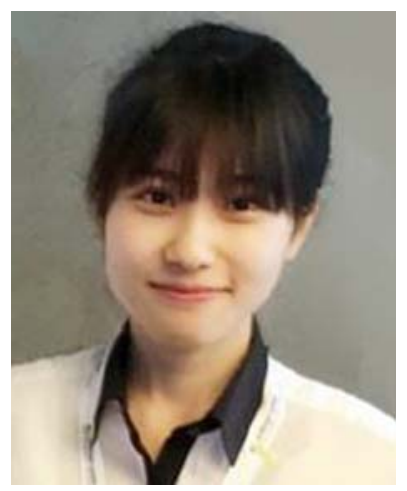

Dr. Jinyi Ge is presently working as a Postdoctoral Research Associate at the Civil \& Environmental Engineering Department, Princeton University. Her research interests are on particle-scale visualization of the evolution of methanogens and methanotrophs, modeling aerobic composting oxygen uptake rate evolution, the characterization of controlled release fertilizer, and estimating thermal balance during composting. She has more than 20 peer-reviewed scientific publications and 6 patents on the following topics: Factory aerobic composting multivariate stereoscopic data real-time acquisition system, Construction of a new model for aerobic composting, A method of digestate co-composting, Method of obtaining characteristic parameters of aerobic composting microstructure, Spiral sampler for aerobic compost material, and Intelligent aerobic composting reactor system. 


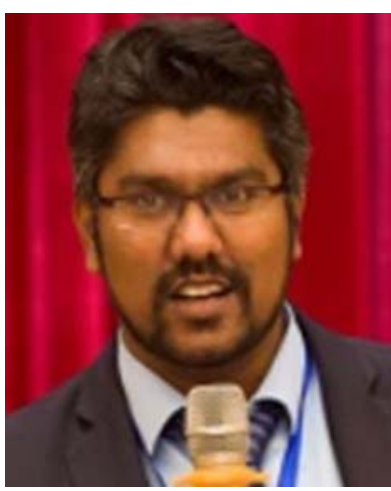

Dr. Gopalakrishnan Kumar is presently working as an Associate Professor at the University of Stavanger, Norway. $\mathrm{He}$ has received his $\mathrm{PhD}$ from Feng Chia University, Taiwan. He was the recipient of the prestigious JSPS postdoctoral fellowship (Japan) and also Emilio Rosenblueth Fellowship (Mexico) for his post-doctoral studies. He is also visiting faculty in many universities in Europe (Hungary, Czech Republic, Poland) and Turkey. He has published more than $225 \mathrm{SCI}$ papers in highly prestigious Journals (including 2 cover image articles and 1 key scientific article), with total citations of $>$ 5200 and $h$-index of 38 . He also contributed to more than 20 book chapters. His major research interest includes biofuel production from lignocellulose/waste/wastewater and algal biomass, microbial fuel/electrolysis cell (MFC \& MEC) technologies. Additionally, he is working on application of green synthesized activated carbon and nanoparticles for various environmental remediation applications. He also delivered more than 100 speeches (keynote/invited) in various conferences, seminars, and workshops.

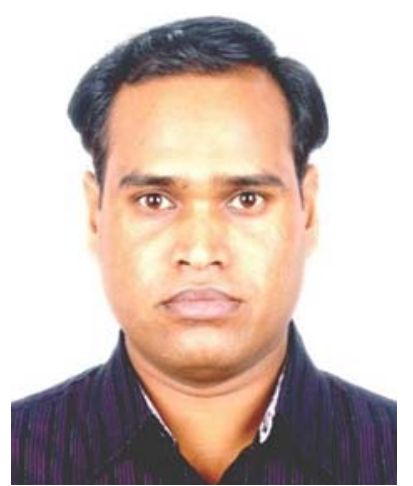

Prof. Rajendra Prasad Singh is working as a Professor at the School of Civil Engineering, Southeast University, Nanjing, China. Currently, he is actively engaged in research related to bioremediation, water and wastewater treatment, sustainable urban water development, sustainable urban water system planning and design; low-impact development; ecological improvement for urban road and public space; real-time control of urban water supply and drainage systems; climate change; urban water environment and water ecosystem restoration; rural ecological protection and restoration; and other environmental pollutionrelated issues. He was the visiting fellow at School of Civil and Environmental Engineering, Purdue University in year 2013. Prof. Singh has published more than 100 research papers in leading SCI/JCR indexed international journals. He is a recipient of the International Young Scientist Fellow Awards of National Natural Science Foundation of
China (NSFC) in 2015 and 2017. Prof. Singh is a member of various academic and non-governmental organization, e.g., the American Society of Civil Engineers (ASCE), Environmental \& Water Resources Institute (EWRI), and International Water Association (IWA). Prof. Singh is also serving as Editorial board member in Water, Bioengineered journals and Review Editor in FEMS journal. He has also served as guest editor in leading SCI/JCR indexed international journals such as Bioresource Technology, International Biodeterioration \& Biodegradation, International Journal of Water Resources Development, Water, Environmental Science and Pollution Research, and Applied Sciences. Prof. Singh was the chair and organizer of the ICWRS-ICAFEE 2018 conference held at Southeast University in Nanjing, China.

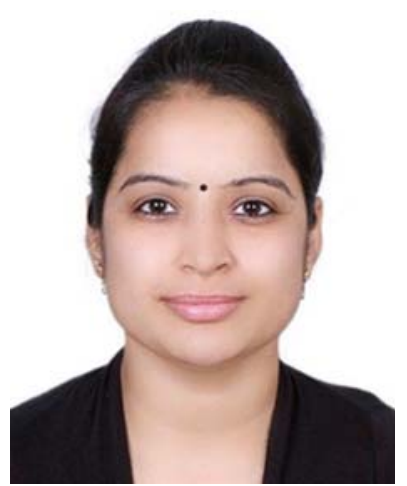

Dr. Sunita Varjani is a Scientific Officer at Gujarat Pollution Control Board, Gandhinagar, Gujarat, India. Her major areas of research are Industrial and Environmental Microbiology/ Biotechnology. She has worked as visiting scientist at EPFL, Lausanne, Switzerland. Dr. Varjani has authored more than 175 publications, including research and review papers, books, book chapters, and conference communications. She has won several awards, including the Young Scientist Awards from Biotech Research Society, India (2018), Microbiologist's Society India (2018-2019), Association of Microbiologists of India (2018), International Society for Energy, Environment and Sustainability (2018), and AFRO-ASIAN Congress on Microbes for Human and Environmental Health, New Delhi (2014); highly cited and highly downloaded papers, Bioresource Technology, Elsevier; Top Reviewer Award-2018, Bioresource Technology, Elsevier; Top Reviewer Award-2017, Bioresource Technology, Elsevier, and Best Paper Awards in national and international conferences in 2008, 2012, 2013, 2018, and 2019. She is a member of the editorial board of Journal of Energy and Environmental Sustainability and has served as guest editor of special issues of Bioresource Technology, ASCE-Journal of Environmental Engineering, Energy and Environment, and others. She is a Management Council Member of the BRSI (www.brsi.in). 